\title{
PERCEPÇÃO DE PACIENTES PÓS-COVID-19 ATENDIDOS NA UTI DE NANUQUE MG A RESPEITO DO TRATAMENTO FISIOTERAPÊUTICO: UM ESTUDO DE CASO.
}

\section{PERCEPTION OF POST COVID-19 PATIENTS ATTENDED AT THE NANUQUE MG ICU REGARDING PHYSIOTHERAPEUTIC TREATMENT: A CASE STUDY.}

\author{
Viviele Santos Nascimento ${ }^{1}$, Patricia Brandão Amorim²
}

\author{
Submetido em: 25/08/2021 \\ Aprovado em: 04/10/2021
}

e29704

https://doi.org/10.47820/recima21.v2i9.704

\begin{abstract}
RESUMO
Introdução: O novo Corona vírus, também chamado de Síndrome da Insuficiência respiratória aguda grave (SRAG), pode ser conceituada como infecções respiratórias que podem agravar no período do inverno, fazendo com que seja comum em adultos e crianças. Seus sintomas variam de febre alta, tosse ou dor de garganta (Mialgia, Cefaleia ou Artralgia). Sua evolução para a síndrome acontece quando o paciente apresenta sintomas mais graves (dispneia, desconforto respiratório, insuficiência respiratória, saturação de oxigênio menor que $95 \%$ e exacerbação de doença preexistente). Objetivo: Analisar a percepção dos pacientes de pós-covid-19 da UTI de NANUQUE-MG a respeito do tratamento fisioterapêutico. Metodologia: Trata-se de uma pesquisa descritiva exploratória do tipo quantitativa realizada em 24 pacientes com idade entre 28 e 75 anos, que tiveram internados na UTI em NANUQUE-MG, apresentando quadro clínico de Covid-19. Foi aplicado um questionário avaliativo com 10 perguntas sobre a recuperação dos pacientes através do tratamento fisioterapêutico. Resultados e discussões: Com o questionário, os pacientes responderam perguntas importantes sobre a doença. As respostas foram analisadas através de gráficos com um percentual necessário, onde foi verificado que a maioria dos pacientes relataram melhora através da fisioterapia. Os pacientes foram orientados ao tratamento fisioterapêutico. Conclusão: conclui-se que pacientes relataram uma percepção do tratamento fisioterápico sendo primordial, devido a sequelas que sofreram com a Covid19. Onde $90 \%$ dos pacientes entrevistados relataram que a fisioterapia foi fundamental no tratamento pós Covid-19. Onde proporcionou o retorno do indivíduo ao mercado de trabalho, relatando também um bom desempenho na AVD'S (Atividade da vida diária).
\end{abstract}

PALAVRAS-CHAVE: Fisioterapia. Covid-19. Tratamento e UTI.

\begin{abstract}
Introduction: The new Corona virus, also called Severe Acute Respiratory Failure Syndrome (SARS), can be defined as respiratory infections that can worsen in the winter period, making it common in adults and children. Its symptoms range from high fever, cough or sore throat (Myalgia, Headache or Arthralgia). Its evolution to the syndrome occurs when the patient has more severe symptoms (dyspnea, respiratory distress, respiratory failure, oxygen saturation less than $95 \%$ and exacerbation of preexisting disease). Objective: To analyze the perception of post Covid-19 patients at the ICU in NANUQUE-MG regarding physical therapy treatment. Methodology: This is an exploratory descriptive study of the quantitative type carried out in 24 patients aged between 28 and 75 years, who were admitted to the ICU in NANUQUE-MG with a clinical picture of Covid-19. An evaluative questionnaire with 10 questions about the patients' recovery through physical therapy treatment was applied. Results and discussion: With the questionnaire, patients answered
\end{abstract}

\footnotetext{
1 Graduanda em fisioterapia, UNEC. Centro Universitário de Caratinga, Campus de Nanuque - MG.

2 Orientadora, UNEC. Doutora em Saúde Pública pela Universidade Americana - Paraguai. Possui mestrado em Meio Ambiente e Sustentabilidade e graduação em Fisioterapia pelo Centro Universitário de Caratinga (2001); Especialização em Autogestão em Saúde pela Fundação Oswaldo Cruz e Fisioterapia Aplicada à Saúde da Mulher pela Universidade Gama Filho. Atualmente é coordenadora do Curso de Fisioterapia do Centro Universitário de Caratinga, na Unidade de Nanuque/MG e professora titular nos demais cursos da área da saúde.
} 


\section{RECIMA21 - REVISTA CIENTÍFICA MULTIDISCIPLINAR ISSN 2675-6218}

PERCEPÇÃO DE PACIENTES PÓS-COVID-19 ATENDIDOS NA UTI DE NANUQUE MG A RESPEITO DO TRATAMENTO FISIOTERAPÊUTICO: UM ESTUDO DE CASO.

important questions about the disease. The answers were analyzed through graphs with a necessary percentage, where it was verified that most patients reported improvement through physical therapy. Conclusion: it is concluded that patients reported a perception of physical therapy treatment being primordial, due to the sequelae they suffered with Covid-19. Where $90 \%$ of interviewed patients reported that physical therapy was essential in post Covid-19 treatment. Where it provided the individual's return to the labor market, also reporting a good performance in AVD'S (Daily Life Activity).

KEYWORDS: Physiotherapy. Covid-19. Treatment and ICU.

\section{INTRODUÇÃO}

O Coronavírus (SARS-CoV-2) apareceu pela primeira vez em 2019, na cidade de Wuhan, em uma província da China. Logo após esta descoberta, as autoridades chinesas relataram um novo tipo de vírus infectante, o Covid-19. Após esse fato, a Organização Mundial da Saúde (OMS) declarou a disseminação do vírus, como uma pandemia, em 11 de março de 2020. Vários estudos sobre essa pandemia, através de comitê internacional de Taxonomia do Vírus, propuseram que o vírus designado seria o sequenciamento genômico da análise filogenética que se trata de um beta coronavírus causada por síndrome da Insuficiência respiratória aguda grave (SARS).

A estrutura do gene do receptor de ligação do vírus nas células é muito semelhante ao do coronavírus e da síndrome da insuficiência respiratória aguda grave (SARS), pois o vírus parece usar o mesmo receptor da enzima 2 de conversão a angiotensina para entrar dentro da célula.

As hospitalizações de pacientes (adolescentes, adultos e idosos) acontecem devido a Síndrome da Insuficiência respiratória aguda grave que pode ser diagnosticada por Covid-19, por ser um vírus causado por uma doença infecciosa, levando muitos pacientes a óbitos (CAMPOS, et.al; 2020).

Pode-se conceituar a Síndrome da Insuficiência respiratória aguda grave (SRAG) como infecções respiratórias que podem agravar no período do inverno, fazendo com que seja comum em adultos e crianças. Seus sintomas variam de febre alta, tosse ou dor de garganta (Mialgia, Cefaleia ou Artralgia). Sua evolução para a síndrome acontece quando o paciente apresenta sintomas mais graves (dispneia, desconforto respiratório, insuficiência respiratória, saturação de oxigênio menor que $95 \%$ e exacerbação de doença preexistente).

A principal forma de transmissão é o contato do indivíduo contaminado por meio de fluidos corporais excreções, secreções e gotículas salivares. O tempo de incubação do vírus acontece de 5 a 14 dias, $80 \%$ dos casos cursam com uma apresentação clínica leve, com febre, dor de garganta, tosse seca, distúrbios gastrointestinais e mialgia, e $20 \%$ evolui para a síndrome do desconforto respiratório agudo, e necessitam de cuidados em unidade de terapia intensiva apresentam a forma mais grave da doença. 


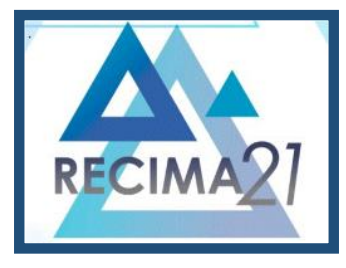

\section{RECIMA21 - REVISTA CIENTÍFICA MULTIDISCIPLINAR ISSN 2675-6218}

PERCEPÇÃO DE PACIENTES PÓS-COVID-19 ATENDIDOS NA UTI DE NANUQUE MG A RESPEITO DO TRATAMENTO FISIOTERAPEUUTICO: UM ESTUDO DE CASO.

Doenças clínicas prévias com hipertensão arterial sistêmica, doenças pulmonares crônicas, cardiovasculares e metabólicas são fatores de risco relacionados à evolução crítica da doença, podendo ser mediadores clínicos de complicações da doença, ou respiração tardia, comparados a aqueles menos graves.

A Covid-19 causa danos ao sistema respiratório por uma resposta inflamatória sistêmica de quadro agudo causado por insultos pulmonares diretos e indiretos. Os sintomas mais comuns no componente respiratório são tosse seca, com pouca exsudação e a redução do índice de oxigenação, provocando dispneia ou aumento do desconforto respiratório, as mudanças no padrão funcional pulmonar interferem na gravidade clínica da doença, colocando em risco a função dos músculos respiratório e intolerância ao exercício físico.

O quadro clínico do Coronavírus (Covid-19) é bem semelhante a certas viroses respiratórias, tais como: febre alta, tosse seca e cansaço. Em casos mais graves podemos caracterizar também: dispneia, sangramento pulmonar, linfopenia grave e insuficiência renal. Nos determinados casos os sintomas podem ser mais leves. Para diagnosticar os casos sintomáticos, confirmados por pesquisas do vírus de reações em cadeias da polimerase (PCR), utilizamos um exame chamado SWAB nasal.

O SWAB nasal é um exame realizado para a detecção do Covid-19, sendo, um cotonete longo e estéreo que é aplicado na região nasal e faríngea. Em casos específicos pode ser realizada como uma lavagem bronco alveolar, onde é realizado dentro do pulmão. É um exame indolor e pode causar desconforto ao atingir o local. O teste deve ser realizado em pacientes sintomáticos ou que tenha tido contato com pessoas infectadas com a Covid-19 até os 7 dias. Outro exame realizado em pacientes com sintomas da Covid-19 é chamado de hemograma completo (sangue), no qual obtemos resultados satisfatórios na descoberta da doença.

A política nacional de educação permanente (PNEP) mostra maneiras para prevenir a Covid-19. Essa prática é definida como aprendizagem no trabalho, sendo notória a capacitação e as estratégias importantes para usar nos serviços de saúde no meio de uma pandemia.

O direcionamento da educação permanente para mudança de concepção e práticas de capacitação dos trabalhadores acarreta a avalição e o manejo de pacientes e cuidados com a biossegurança. A coleta de materiais para os exames diagnósticos são: aspirador nasofaringes, SWAB nasal e oral. Esses exames são importantes para descoberta da Covid-19 (DIAS et. al; 2020).

Em Nanuque/MG existe uma equipe especializada para atender os pacientes diagnosticados pela covid-19. A UTI (Unidade de Terapia Intensiva) possui uma equipe multidisciplinar tais como: médicos plantonistas, psicólogos, nutricionistas, enfermeiros, fonoaudiólogos, fisioterapeutas, farmacêuticos e terapeutas ocupacionais. Com objetivo de melhorar a saúde desses pacientes. 


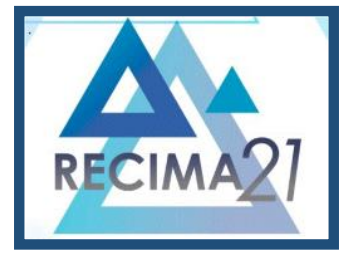

\section{RECIMA21 - REVISTA CIENTÍFICA MULTIDISCIPLINAR ISSN 2675-6218}

PERCEPÇÃO DE PACIENTES PÓS-COVID-19 ATENDIDOS NA UTI DE NANUQUE MG A RESPEITO DO TRATAMENTO FISIOTERAPÊUTICO: UM ESTUDO DE CASO.

É muito importante, tanto para o paciente como para a família, compreender a UTI como etapa fundamental para a superação da doença, porém, tão importante é aliviar e proporcionar conforto independente do prognóstico. A equipe está orientada, no respeito, a dignidade e autodeterminação de cada pessoa internada, estabelecendo e divulgando a humanização dos seus trabalhos, buscando amenizar os momentos vivenciados através do paciente e família (MORAES, et. al; 2021).

O estudo teve o objetivo de abordar o trabalho da fisioterapia em pacientes que sofreram com a Covid-19. Vamos mostrar que o trabalho do fisioterapeuta se baseia nos cuidados e na prevenção contra essa doença. $O$ objetivo desse estudo é abordar o tratamento fisioterapêutico em pacientes pós Covid-19. A fisioterapia estabelece um papel fundamental para esse tratamento, utilizando técnicas para um bom controle respiratório, controle de tronco, membros superiores e inferiores, condicionamento e fortalecimento do paciente.

A fisioterapia tem um papel importante na UTI (Unidade de terapia intensiva), pois atua na linha de frente com métodos de prevenção, reabilitação dos agravos pulmonares e limitações das atividades de vida diárias adquiridas no período do tratamento do paciente. Cada paciente apresenta comprometimento multissistêmicos causados pela doença e pela disfunção muscular adquirida na hospitalização.

\section{FUNDAMENTAÇÃO TEÓRICA}

A síndrome respiratória aguda, também chamado de Corona vírus (Covid-19) foi identificada em dezembro de 2019 como causa grande numa série de casos de pneumonia na China. O número de casos vem aumentando desde janeiro de 2020 (OMS, 2020).

O coronavírus (Covid-19) é uma doença denominada por SARS-COV-2, que apresenta um aspecto clínico variando de infecções assintomáticas a quadro graves. De acordo com a organização mundial de saúde, a maioria dos pacientes com Covid-19 podem ser assintomáticos ou olígossintomáticos e aproximadamente $20 \%$ dos casos detectados requer atendimento hospitalar por apresentar dificuldades respiratórias dos quais aproximadamente $5 \%$ podem necessitar de suporte ventilatório (CHASQUEIRA \& SILVA, 2021).

\subsection{Fisiologia do coronavírus (COVID-19)}

O SARS-COV-2 é um beta-coronavírus da RNA da fita simples de sentido positivo com o núcleo capsídeo. Seu receptor, na superfície celular do hospedeiro é enzima conversora da angiotensina 2 (ACE2). A ACE2 é uma proteína de membrana tipo 1 expressa em células nos rins, coração, TGI, vasos sanguíneos e, principalmente, células epiteliais alveolares AT2 pulmonares, que são particularmente propensas a infecções virais (COSTA, et.al; 2020).

A estrutura do SARS-COV2, coronavírus 2 da síndrome respiratória aguda grave, é constituída por: envelope, proteína $E$, hemaglutinina-esterase, proteína $M$, proteína $S$ (Spike) e 


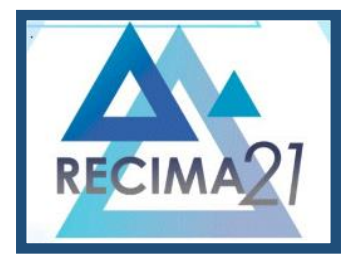

\section{RECIMA21 - REVISTA CIENTÍFICA MULTIDISCIPLINAR ISSN 2675-6218}

PERCEPÇÃO DE PACIENTES PÓS-COVID-19 ATENDIDOS NA UTI DE NANUQUE MG A RESPEITO DO TRATAMENTO FISIOTERAPEUUTICO: UM ESTUDO DE CASO.

proteína N. As proteínas S e $\mathrm{N}$ exercem funções cruciais na patogenia do Covid-19. A Spike (S) é a quem se ancora aos receptores de ECA2 para posterior entrada nos pneumócitos das células epiteliais respiratórias. Já a proteína $\mathrm{N}$, além de ser responsável pela replicação viral, ela é fortemente produzida durante a infecção, se constituindo como a principal causa da alta imunogenicidade do vírus (COSTA, et.al; 2020).

A nomenclatura dos vírus e doenças sugere diretrizes que indicam evitar referências a uma localização geográfica, um animal, um indivíduo ou grupo de pessoas. Entre os sintomas da Covid19 estão febres, cansaço, tosse seca e falta de ar. Alguns pacientes podem sentir dores na garganta, diarreia, congestão nasal e dores no corpo (SALES, et.al; 2020).

\subsection{Transmissão do coronavírus (Covid-19)}

A transmissão do SARS-CoV-2 ocorre, principalmente, através de gotículas respiratórias e do contato direto com as membranas mucosas, a infecção pode ocorrer se a pessoa tocar uma superfície infectada e depois tocar nos olhos, nariz ou boca. As gotículas podem alcançar até dois metros e não permanecem no ar; no entanto, o SARS-CoV-2 é viável em aerossóis em condições experimentais por pelo menos três horas (CUNHA \& SILVA, 2021).

Destaca-se a evidente possibilidade de que o SARS-CoV-2 também seja transmitido durante o período de incubação do vírus - que é de cerca de 14 dias, com a maior parte dos casos apresentando sintomas no $4^{\circ}$ ou $5^{\circ}$ dia após a infecção. Logo, pessoas assintomáticas funcionam com fontes potenciais de infecção. Além disso, a forma de transmissão oral fecal foi considerada após o RNA do SARS-Cov-2 ter sido detectado em amostras de sangue e fezes (entretanto, não é fator significativo de disseminação) (CHASQUEIRA \& SILVA, 2021).

A mensuração do grau de infectividade do vírus é feita através da comparação com outras doenças respiratórias similares, como a Influenza e a SARS-Cov-2. Desta forma, é possível analisar o tempo de infecção por indivíduo, viabilizando o tempo que o indivíduo deve ficar em isolamento, evitar transmissão, e determinar faixa etária mais suscetível sem que sejam necessários estudos epidemiológicos de grande escala (PASCOAL, et.al; 2020).

O período infeccioso do Covid-19 é semelhante ao da influenza. O período infeccioso da influenza é de cerca de 4-8 dias dependendo da carga viral, a maior parte da transmissão seria nos primeiros dias de infecção (2-3 dias). Em crianças, este período é mais lento, aumentando a capacidade de transmissibilidade entre as populações (SINHA \& BALAYLA, 2020).

Os sintomas da primeira semana são mialgia, febre, desconforto na laringe e outros sistêmicos e o aumento da carga viral nesta semana sugere que os sintomas são amplamente relacionados à replicação viral e a citólise (CUNHA, 2021).

Para evitar o contato direto com os pacientes que suspeitam ter a doença é sempre recomendado pelos profissionais de saúde o uso contínuo de máscara e de equipamento de proteção individual (ARARUNA, et.al; 2021). 


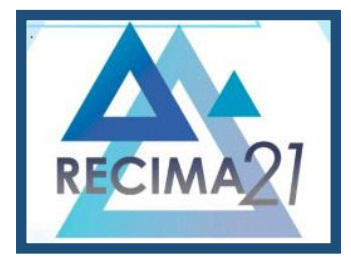

\section{RECIMA21 - REVISTA CIENTÍFICA MULTIDISCIPLINAR ISSN 2675-6218}

A ausência da efetividade diante a uma doença nova, faz com que as estratégias sejam limitadas. As máscaras são barreiras físicas efetivas para limitar a transmissão da doença nas pessoas (GARCIA, 2020).

\subsection{Sinais e sintomas do coronavírus (Covid-19)}

Existem certos sinais e sintomas que atingem o processo imunológico do paciente, como: febre, tosse seca e cansaço. Outros sintomas são menos comuns nesses pacientes como: dores e desconforto, dor de garganta, diarreia, conjuntivite, dor de cabeça, perda de paladar ou olfato e erupção cutânea na pele ou descoloração dos dedos das mãos ou dos pés. Os mais graves são: dificuldade de respirar ou falta de ar, dor ou pressão no peito, perda de fala ou movimento (SALLA, et.al; 2020).

Em média os sintomas aparecem após 5 a 6 dias depois de ser infectado com o vírus, porém isso pode levar até 14 dias. Pacientes com comprometimento respiratório ou cardíaco podem ficar um período na UTI, tomando todas as medidas e cuidados, junto aos profissionais capacitados para apresentar um bom atendimento, já outros não resistem e chegam a ir a óbito, devido a um histórico de doença já existente no paciente, e também, por falta de equipamentos importantes para obtenção desses cuidados (CHASQUEIRA \& SILVA, 2021).

\subsection{Quadros clínico da Covid-19}

Os principais sintomas apresentados foram febres, fadiga e tosse seca. Apesar da febre ser um achado considerável na maioria dos pacientes com o quadro elevado da infecção, em alguns casos, em pacientes que estão na fase aguda da infecção a febre pode estar ausente. A ausência de febre na Covid-19 é mais frequentes do que na infecção por MERS-CoV e SARS-CoV-2. Logo, pacientes afebris podem ser despercebidos se o diagnóstico se concentrar na detecção da febre. Além desses sintomas, os pacientes também podem apresentar Linfocitopenia, trombocitopenia, leucopenia, elevados níveis de proteína $C$ reativa, níveis elevados de alanina aminotransferase, aspartato, creatina quinase e ferritina elevada, náusea, vômitos, diarreias, cefaleia, gastroenterite e odinofagia, também podem estar presentes (CRISTÓVAM, et.al; 2020).

$\mathrm{Na}$ apresentação clínica da sintomatologia, soma-se a presença de comorbidades associadas (diabetes, hipertensão, DPOC). As tomografias computadorizadas (TC) apresentam anormalidades em alguns casos, prevalecendo à opacidade em vidro fosco, como achado radiológico, além de sombreamento bilateral irregular. Existe ainda a possibilidade de nenhuma anormalidade radiográfica ou tomográfica a ser encontrada (DIAS, et.al; 2020).

Nos piores momentos da doença, os primeiros casos surgiram em indivíduos assintomáticos, com diagnóstico laboratorial confirmado, mas essa triagem de assintomáticos por meio de testes moleculares mostrou-se complexa, uma vez que a conduta em casos suspeitos varia 


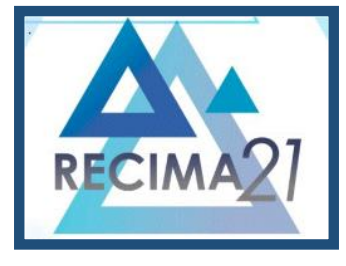

\section{RECIMA21 - REVISTA CIENTÍFICA MULTIDISCIPLINAR ISSN 2675-6218}

PERCEPÇÃO DE PACIENTES PÓS-COVID-19 ATENDIDOS NA UTI DE NANUQUE MG A RESPEITO DO TRATAMENTO FISIOTERAPEUUTICO: UM ESTUDO DE CASO.

em diferentes países. Esse desafio se torna ainda mais considerável na observação de casos pediátricos, que contribuem para grande parte dos portadores assintomáticos, exigindo maior atenção para evitar a transmissão (SINHA \& BALAYLA, 2020).

No entanto, os sintomas são mais evidentes em pacientes com testes moleculares positivos e com manifestações respiratórias e exames de imagem compatíveis com o diagnóstico de pneumonia. Os registros clínicos dos pacientes no início da infecção indicam que os sintomas mais comuns são febres, tosse, mialgia e fadiga, e também podem ser acompanhados por secreção respiratória, dor de cabeça, hemoptise e diarreia (FERREIRA, et al; 2020).

Alguns sintomas iniciais se assemelham aos de outras infecções respiratórias virais, como Norovirose e Influenza. Dispneia e febre alta são sintomas que definem a principal diferença clínica entre a Covid-19 e o resfriado comum, que é acompanhado de congestão nasal, lacrimejamento, espirros e coriza, inicialmente hialina, mas que ao longo dos dias se torna amarelo-esverdeada. Por outro lado, quando comparada com a infecção por Influenza, a Covid-19 apresenta sintomas clínicos semelhantes, mas com maior proporção de evoluções para infecções graves e críticas, exigindo oxigeno terapia e suporte ventilatório (FERREIRA, et al; 2020).

A maioria dos pacientes progride com um bom prognóstico. É essencial destacar que em idosos ou indivíduos com comorbidades anteriores, como diabetes, doenças cardiovasculares e renais, a Covid-19 pode progredir de forma mais agressiva, com pneumonia e síndrome do desconforto respiratório agudo (SDRA) além de disfunção cardíaca, hepática e renal (RAIOL,2020).

Pacientes com sinais e sintomas como febre alta, taquipneia e dispneia, além de indicações clínicas da gravidade exigem maior atenção da equipe médica. A progressão dos primeiros sintomas de Covid-19 para sepse é lenta, e o envolvimento extrapulmonar é caracterizado principalmente por insuficiência cardíaca refratária e danos nos rins (STRABELLI \& UIP, 2020).

\subsection{Importâncias da fisioterapia no tratamento dos pacientes pós-covid-19}

A fisioterapia é muito importante em pacientes pós-covid-19, pois ela contribui para evitar complicações cardiorrespiratórias e motoras, ajuda na recuperação da funcionalidade, melhorando a falta de ar, a fraqueza muscular e reestabelecimento de massa muscular, porém ainda não é possível afirmar o tempo de recuperação dos pacientes. Os idosos e portadores de doenças cerebrovasculares e cardiovasculares, necessitam de uma reabilitação mais protegida (SARAIVA et al; 2020).

Algumas estratégias são importantes para trabalhar com os pacientes que apresentam a Covid-19, como por exemplo, estratégias de mobilização e exercícios terapêuticos. Certos pacientes que recebem alta de unidade de terapia intensiva (UTI) devem receber alguns cuidados importantes para que o paciente consiga seguir a sua vida diária normalmente. Por isso, os fisioterapeutas são importantes para cuidar desses pacientes com Covid-19, através de exercícios respiratórios, condicionamento físico e de fortalecimento muscular (KARSTEN \& MATTE, 2020). 


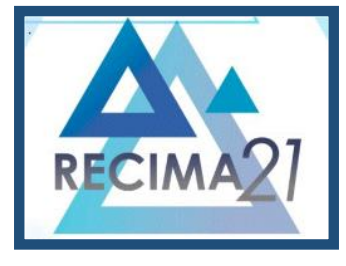

\section{RECIMA21 - REVISTA CIENTÍFICA MULTIDISCIPLINAR ISSN 2675-6218}

PERCEPÇÃO DE PACIENTES PÓS-COVID-19 ATENDIDOS NA UTI DE NANUQUE MG A RESPEITO DO TRATAMENTO FISIOTERAPEUUTICO: UM ESTUDO DE CASO.

Em virtude do alto risco para desenvolvimento da fraqueza muscular adquirida na unidade de terapia intensiva (UTI) e potencial declínio funcional. Recomenda-se que sempre que houver viabilidade clínica recursos humanos e técnicos disponíveis um protocolo sistemático de mobilização ou exercícios terapêuticos seja aplicado nos pacientes com Covid-19 (SARAIVA et al; 2020).

\subsection{Tratamentos dos pacientes pós-covid-19}

Para dar início ao tratamento fisioterapêutico com pacientes pós-covid-19, primeiramente é feita uma orientação necessária para que a família tenha conhecimento da doença. A prevenção é muito importante, como por exemplo, uso de máscara, lavar as mãos com frequência, usar álcool em gel ou álcool 70\%, manter distância segura de pessoas com quem tiver contato, especialmente pessoas que espirram e tossem com frequência, não tocar nos olhos, nariz e boca, cobrir o nariz $e$ a boca com a máscara apropriada (KARSTEN \& MATTE, 2020).

Algumas técnicas são importantes para cuidar desses pacientes, como por exemplo: exercícios fisioterapêuticos, administração e colocação de oxigênio, assistência técnica e intervenções envolvendo intubações, ventilação mecânica e mudança de decúbitos, procedimentos para a remoção de secreção brônquica e melhorar função respiratória (NAGAMINE, et. al. 2021).

O trabalho da fisioterapia motora é importante e necessário na recuperação dos pacientes que ficam pouco tempo internados no leito. Esses pacientes requerem um acompanhamento mais de funcionalidade e sustentação dos músculos articulatórios e cardiorrespiratórios (CARMO, et. al. 2020).

Os exercícios de condicionamento respiratório podem ser feitos com uso de esteira ou bicicleta, exercício respiratório para melhorar a mobilidade do diafragma, favorecer a drenagem torácica, recuperar a capacidade pulmonar. Alguns exercícios são necessários: exercício de respiração, abdominal, diafragma, exercício de resistência, exercício de sustentação e exercício com elevação dos braços, uso do canudinho e mobilização (NAGAMINE, et. al. 2021).

Nas unidades de terapia intensiva, as intervenções do fisioterapeuta incluem o manejo respiratório e o gerenciamento da postura do paciente, além da realização de atividades de mobilização para evitar complicações decorrentes de imobilidade. Quando a condição do paciente permite, o fisioterapeuta é o responsável por garantir períodos de ortostatismo para facilitar a função cardiorrespiratória (GUIMARÃES, 2020).

O procedimento consiste em elevar a cabeceira da cama até para a posição sentada durante 30 minutos, três vezes ao dia. Outro exemplo de troca postural realizada pelo fisioterapeuta é a pronação, manobra que consiste em deixar o indivíduo de barriga para baixo, de modo a evitar o acúmulo de secreção na base do pulmão, reativar as vias aéreas e reduzir a sobrecarga cardíaca. Dependendo do grau de sedação do paciente, o profissional pode realizar ainda treinamentos ativos 


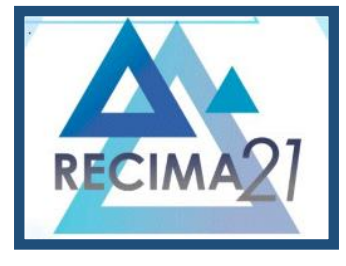

\section{RECIMA21 - REVISTA CIENTÍFICA MULTIDISCIPLINAR ISSN 2675-6218}

PERCEPÇÃO DE PACIENTES PÓS-COVID-19 ATENDIDOS NA UTI DE NANUQUE MG A RESPEITO DO TRATAMENTO FISIOTERAPÊUTICO: UM ESTUDO DE CASO.

ou passivos envolvendo movimento articular, alongamentos e estimulação elétrica neuromuscular (FES) (CARMO, et. al. 2020).

Antes da escolha dos recursos e técnicas fisioterapêuticas, o fisioterapeuta deve considerar as indicações e contraindicações de cada uma delas, sempre considerando os riscos e as particularidades de cada paciente. Além das técnicas voltadas para a melhora da respiração, os fisioterapeutas também realizam intervenções que estimulam a mobilidade do paciente. Como eles passam muito tempo na mesma posição, é importante ações que promovam a amplitude articular, assim como sequelas que estimulam o movimento (SILVA, et. al. 2020).

\section{PROCEDIMENTOS METODOLÓGICOS}

Trata-se de uma pesquisa descritiva exploratória do tipo quantitativa, realizada em 24 pacientes com idade entre 25 e 75 anos, que tiveram internados na UTI em NANUQUE-MG apresentando Covid-19. Foi aplicado um questionário avaliativo sobre a recuperação dos pacientes através do tratamento fisioterapêutico.

Esse questionário avaliativo obteve questões necessárias para que o fisioterapeuta iniciasse 0 tratamento com esses pacientes. As perguntas envolvem descoberta da doença; sintomas apresentados; tipo de sequelas apresentada no pós Covid-19; após a alta hospitalar foi orientado o tratamento fisioterapêutico; antes do tratamento como você estava; usou equipamento de ventilação mecânica (intubação); se o paciente foi participativo e colaborativo durante o seu tratamento; no período de internação o paciente teve ajuda do fisioterapeuta; seu tratamento foi eficaz com a fisioterapia e qual a expectativa do paciente em relação ao tratamento fisioterapêutico.

\section{RESULTADOS E DISCUSSÃO}

A Covid-19 é uma doença aguda resolvível, mas que, também, pode ser mortal, principalmente para grupo de risco, como idosos e pessoas diagnosticadas com doenças crônicas ou prévias (hipertensão arterial sistêmica e diabetes), com taxa de mortalidade elevada. Quando considerada grave, a doença causa danos alveolar maciço e insuficiência respiratória progressiva (STRABELLI \& UIP, 2020).

Para possível tratamento da doença, podemos apresentar alguns autocuidados necessários, como: ligue para seu prestador de cuidados de saúde ou para uma central de informações sobre a doença para descobrir onde e quando você pode fazer um teste; informe outras com quem você teve contato para impedir a propagação do vírus; caso não seja possível fazer o teste, fique em casa e pratique o distanciamento social por 14 dias; enquanto estiver de quarentena, não vá ao trabalho, a escola ou a espaços públicos (ROLIM, et. al. 2020).

Peça para alguém levar itens essenciais até você; mantenha pelo menos um metro de distância de outras pessoas, incluindo membros da sua família; use máscara para proteger os outros, até mesmo quando você precisar procurar atendimento médico; higienize as mãos com 


\section{RECIMA21 - REVISTA CIENTÍFICA MULTIDISCIPLINAR ISSN 2675-6218}

PERCEPÇÃO DE PACIENTES PÓS-COVID-19 ATENDIDOS NA UTI DE NANUQUE MG A RESPEITO DO TRATAMENTO FISIOTERAPÊUTICO: UM ESTUDO DE CASO.

frequência; fique em um cômodo separado dos outros membros da sua família. Se isso não for possível, use máscara; mantenha o ambiente bem ventilado; se você divide quarto com alguém, deixe um metro de distância entre as camas; preste atenção por 14 dias para ver se você apresenta sintomas; ligue para o prestador de cuidados de saúde imediatamente se você apresentar qualquer um destes sintomas: dificuldade para respirar, perda da fala ou da mobilidade, contusão ou dores no peito e mantenha contato com seus entes queridos por telefones ou on-line e faça exercícios para manter o pensamento positivo (NETO, et. al. 2020).

Outros tratamentos médicos são receitados, como: tratamentos paliativos mais indicados incluem oxigênio, para casos mais graves e pacientes de alto risco devido a outras doenças, e suportes respiratórios, como ventilação, para pacientes em estado críticos. A dexametasona é um corticosteroide que pode ajudar a reduzir o tempo de ventilação e salvar as vidas de pacientes em situação mais grave. A organização mundial da saúde não recomenda a automedicação, incluindo ingestão de antibióticos, como prevenção ou cura da Covid-19 (SCHUJMANN ,2021).

Com o questionário, os pacientes responderam perguntas importantes sobre a doença. As respostas foram analisadas através de gráficos com um percentual necessário para saber como que a fisioterapia se torna importante para o tratamento da doença. Todos os pacientes foram orientados ao tratamento fisioterapêutico.

Foram entrevistados 24 pacientes, sendo que 41,6 , \% são mulheres e 58,3\% são homens. Destes, as mulheres tinham idade de 35 a 72 anos, os homens entre 28 a 75 anos. 


\section{RECIMA21 - REVISTA CIENTÍFICA MULTIDISCIPLINAR ISSN 2675-6218}

PERCEPÇÃO DE PACIENTES PÓS-COVID-19 ATENDIDOS NA UTI DE NANUQUE MG A RESPEITO DO TRATAMENTO FISIOTERAPÊUTICO: UM ESTUDO DE CASO. Viviele Santos Nascimento, Patricia Brandão Amorim

Gráfico 1 - A descoberta do paciente quando apresentou a Covid-19.

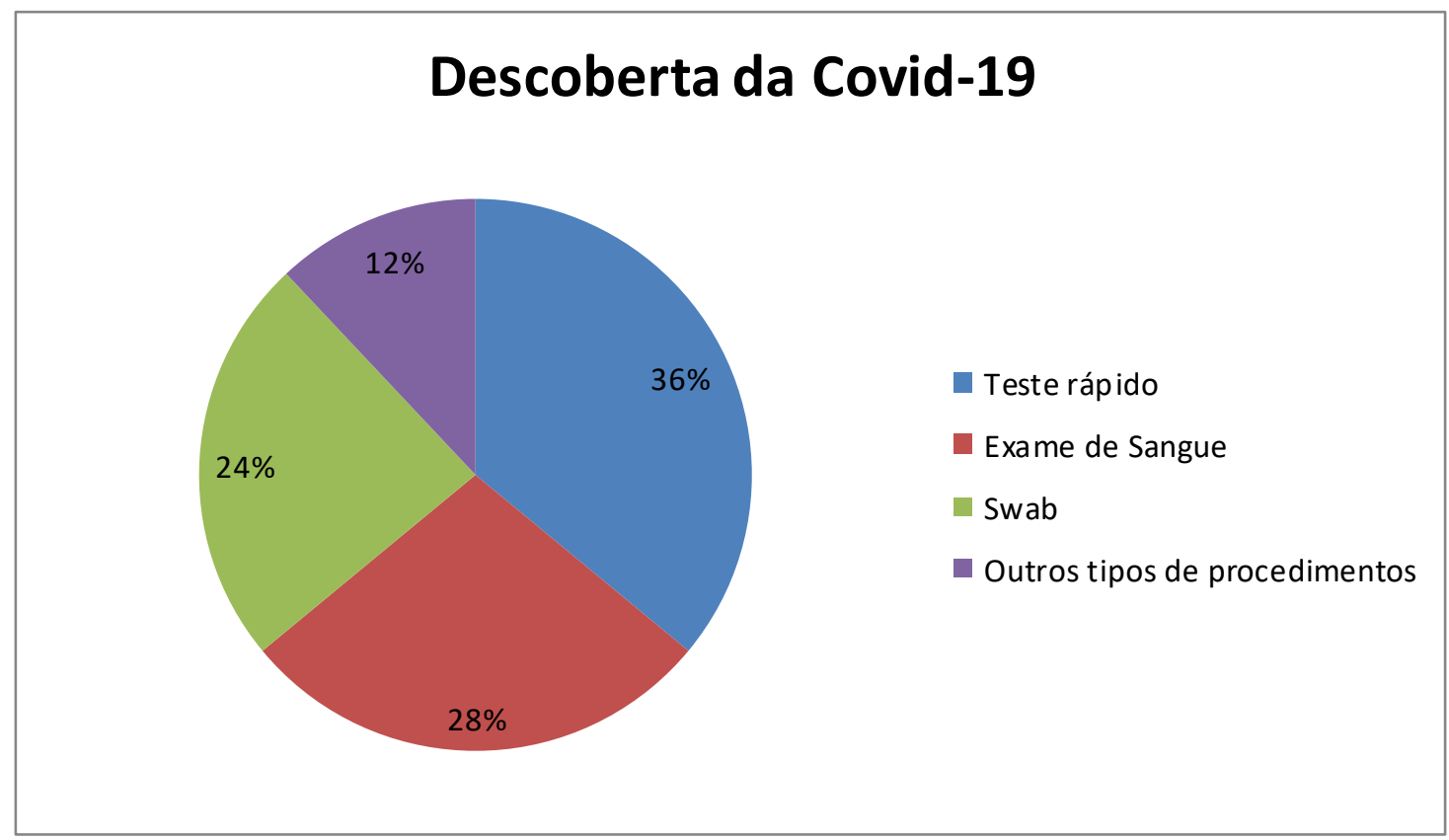

Fonte: Dados da pesquisa

No gráfico 1 perguntou-se aos pacientes como foi diagnosticado a Covid-19. Alguns pacientes responderam que $36 \%$ realizaram um teste rápido, $28 \%$ realizaram exame de sangue, $24 \%$ realizaram o Swab e $12 \%$ disseram que realizaram outros tipos de procedimentos.

A realização dos testes para a descoberta da Covid-19 é uma das formas mais eficazes de controlar a pandemia, enquanto a vacina ainda não está em uso. Embora eles não sejam as únicas alternativas para diagnóstico da doença, são essenciais para se ter um conhecimento mais real sobre o verdadeiro índice de infectados (DIAS, et.al; 2020). 


\section{RECIMA21 - REVISTA CIENTÍFICA MULTIDISCIPLINAR ISSN 2675-6218}

PERCEPÇÃO DE PACIENTES PÓS-COVID-19 ATENDIDOS NA UTI DE NANUQUE MG A RESPEITO DO TRATAMENTO FISIOTERAPÊUTICO: UM ESTUDO DE CASO.

Gráfico 2 - Tipo de sintomas que o paciente apresentou antes da internação hospitalar.

\section{Sintomas da Covid-19}

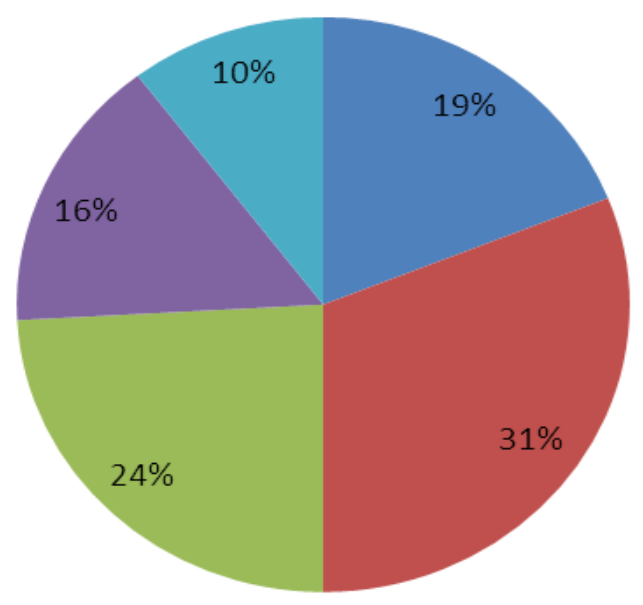

- febre alta

tosse seca

dificuldade de respirar

- dores musculares e nas articulações

- cansaço, diarréia e dores na garganta

Fonte: Dados da pesquisa.

No gráfico 2 perguntou-se sobre o tipo de sintomas que os pacientes apresentaram antes da internação hospitalar. Os pacientes disseram que 31\% tiveram uma tosse seca; $24 \%$ tiveram dificuldade de respirar; 19\% tiveram febre alta; 16\% tiveram dores musculares e nas articulações e $10 \%$ tiveram cansaço, diarreia e dores na garganta.

A nova corona vírus, o SARC-VoV-2, responsável pela Covid-19, pode causar vários sintomas diferentes que, dependendo da pessoa, podem variar desde uma simples gripe até uma pneumonia grave. Normalmente os primeiros sintomas da covid-19 aparecem 2 a 14 dias após uma possível exposição ao vírus, e incluem: tosse seca e persistente; febre alta; cansaço excessivo; dor muscular generalizada; garganta inflamada; coriza ou nariz entupido; alterações do trânsito intestinal; principalmente diarreia; perda de gosto e olfato (TESINI, 2020). 


\section{RECIMA21 - REVISTA CIENTÍFICA MULTIDISCIPLINAR ISSN 2675-6218}

PERCEPÇÃO DE PACIENTES PÓS-COVID-19 ATENDIDOS NA UTI DE NANUQUE MG A RESPEITO DO TRATAMENTO FISIOTERAPEUUTICO: UM ESTUDO DE CASO.

Gráfico 3 - Apresentação do tipo de sequelas que o paciente tem no pós Covid-19.

\section{Tipo de sequelas da covid-19}

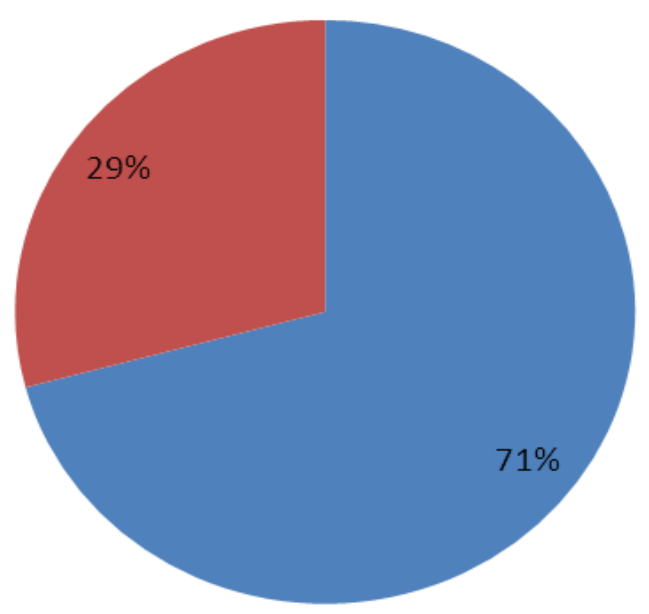

- $\operatorname{sim}$ (depressão, perda de memória, perda de cabelo, problemas do coração, perda da funcionalidade e fraqueza muscular)

n não (sem alterações)

Fonte: Dados da pesquisa.

No gráfico 3 perguntou-se se os pacientes apresentaram algum tipo de sequelas no pós Covid-19. Os pacientes responderam, $71 \%$ disseram que sim e $29 \%$ disseram que não. Aqueles que responderam sim podem apresentar sequelas como depressão, perda de memória, perda de cabelo, problemas no coração, perda da funcionalidade e fraqueza muscular.

Além do risco maior de não sobreviver, uma série de outros problemas de saúde foi citada como consequência da Covid-19. Por exemplo: sequelas no sistema respiratório, no sistema nervoso, distúrbios neuro cognitivos, de saúde mental, metabólicos, cardiovasculares e gastrointestinais (SALES et al., 2020). 


\section{RECIMA21 - REVISTA CIENTÍFICA MULTIDISCIPLINAR ISSN 2675-6218}

PERCEPÇÃO DE PACIENTES PÓS-COVID-19 ATENDIDOS NA UTI DE NANUQUE MG A RESPEITO DO TRATAMENTO FISIOTERAPÊUTICO: UM ESTUDO DE CASO.

Gráfico 4 - Após a alta hospitalar o paciente buscou ajuda da fisioterapia para o tratamento.

\section{Após a alta hospitalar buscou ajuda da fisioterapia para o tratamento}

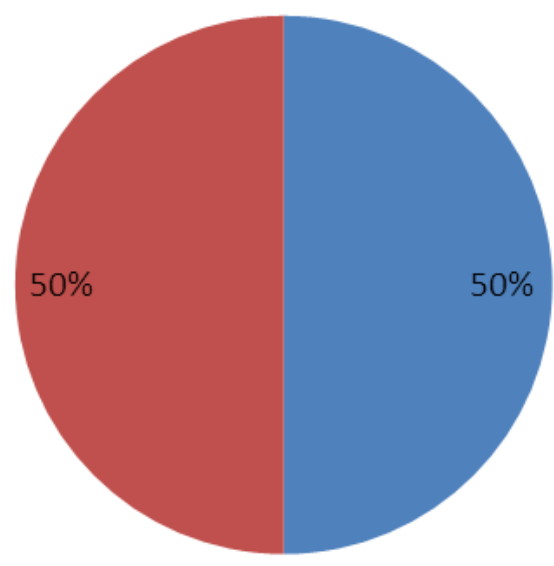

Fonte: Dados da pesquisa.

No gráfico 4 avaliou-se se o paciente buscou a ajuda da fisioterapia após a alta hospitalar para o tratamento. $50 \%$ desses pacientes responderam que sim e $50 \%$ desses pacientes responderam que não. Esses pacientes geralmente recebem orientações de certos profissionais de saúde sobre alguns tratamentos importantes para a sua recuperação.

A fisioterapia após a alta hospitalar tem como objetivo melhorar a capacidade pulmonar, prevenindo possíveis complicações respiratórias, além de promover ganho de força muscular, condicionamento físico, equilíbrio e melhora funcional, visando a maior independência e retorno às atividades habituais. Importante ser realizada por um profissional devidamente qualificado. $\mathrm{O}$ atendimento deve ser individualizado, com metas claras a serem alcançadas a curto, médio e longo prazo, podendo ser modificadas de acordo com a evolução clínica do paciente (MARTINEZ et. al, 2020). 


\section{RECIMA21 - REVISTA CIENTÍFICA MULTIDISCIPLINAR ISSN 2675-6218}

PERCEPÇÃO DE PACIENTES PÓS-COVID-19 ATENDIDOS NA UTI DE NANUQUE MG A RESPEITO DO TRATAMENTO FISIOTERAPÊUTICO: UM ESTUDO DE CASO.

Gráfico 5 - Percepção do paciente a respeito de sua saúde.

\section{Como você estava antes de começar a fisioterapia.}

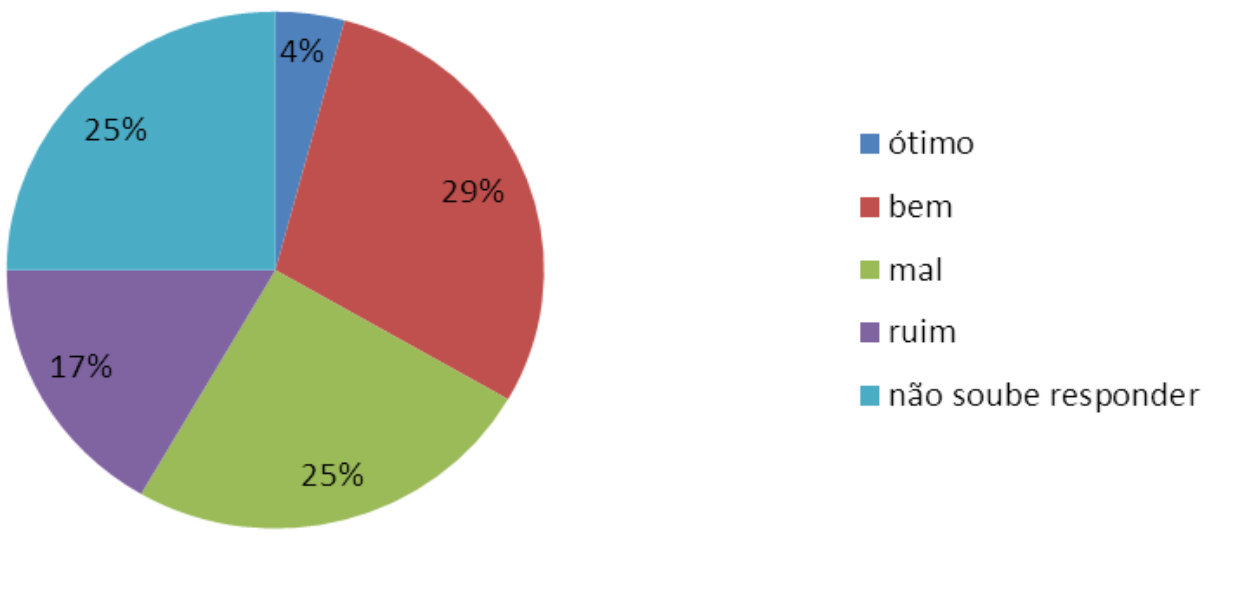

Fonte: Dados da pesquisa.

No gráfico 5 perguntou-se sobre o estado de saúde antes de começar a fisioterapia. Alguns pacientes responderam que 29\% estão bem; 25\% estão mal; 25\% não souberam responder; $17 \%$ estão ruins e $4 \%$ estão ótimos. Este tipo de pacientes geralmente se sente com fraqueza nos músculos e nas articulações, dificuldade de deambular, dificuldade na fala e na deglutição.

A avaliação fisioterápica avalia desde simples aspectos físicos, como alterações, deformidades aparentes e postura, os mais elaborados, como os movimentos do corpo no geral. Além de avaliar o corpo e a situação de cada músculo e osso do paciente, a avaliação costuma também observar e analisar aspectos psicológicos, sociais, familiares e emocionais, entre outros que podem trazer informações úteis. Diferente do diagnóstico médico, por exemplo, a avaliação fisioterápica é complementar justamente porque busca analisar cada caso de maneira global, incluindo todos os pontos que podem influenciar de alguma maneira durante o tratamento (LIMA et. al, 2020). 


\section{RECIMA21 - REVISTA CIENTÍFICA MULTIDISCIPLINAR ISSN 2675-6218}

PERCEPÇÃO DE PACIENTES PÓS-COVID-19 ATENDIDOS NA UTI DE NANUQUE MG A RESPEITO DO TRATAMENTO FISIOTERAPÊUTICO: UM ESTUDO DE CASO. Viviele Santos Nascimento, Patricia Brandão Amorim

Gráfico 6 - Equipamento de ventilação mecânica (intubação).

\section{Você precisou usar equipamentos de ventilação mecânica (intubação).}

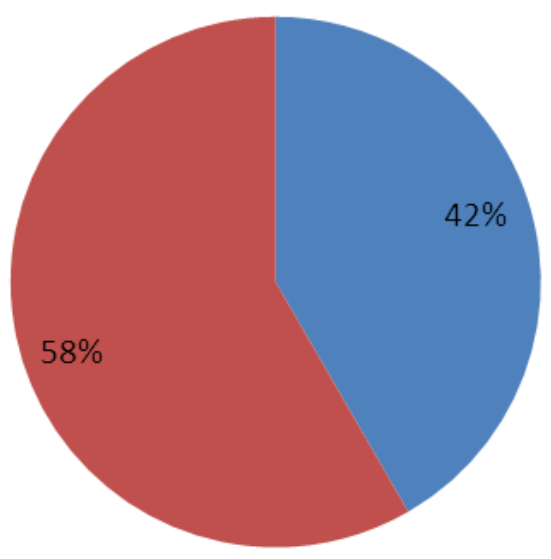

Fonte: Dados da pesquisa.

No gráfico 6 perguntou-se se o paciente precisou usar equipamentos de ventilação mecânica (intubação). Os pacientes responderam que $58 \%$ não utilizaram esses equipamentos e $42 \%$ sim, utilizaram os equipamentos de ventilação.

Ventilação mecânica é o suporte oferecido, por meio de um aparelho, ao paciente que não consegue respirar espontaneamente por vias normais devido a fatores como doenças, anestesia $\mathrm{e}$ anomalias congênitas (SINHA \& BALAYLA, 2020). 


\section{RECIMA21 - REVISTA CIENTÍFICA MULTIDISCIPLINAR ISSN 2675-6218}

PERCEPÇÃO DE PACIENTES PÓS-COVID-19 ATENDIDOS NA UTI DE NANUQUE MG A RESPEITO DO TRATAMENTO FISIOTERAPÊUTICO: UM ESTUDO DE CASO.

Gráfico 7 - Participação e colaboração do paciente em relação ao tratamento fisioterapêutico.

\section{Você tem sido participativo e colaborativo com o tratamento fisioterápico.}

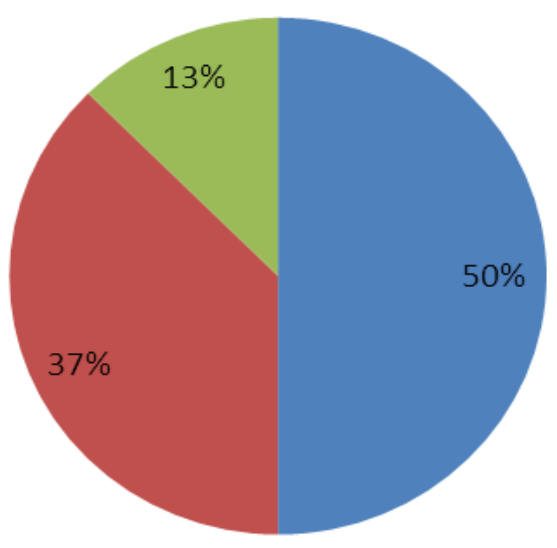

sim

não

não realizou tratamento fisioterápico

Fonte: Dados da pesquisa.

No Gráfico 7 perguntou-se ao paciente se ele tem sido participativo e colaborativo com o tratamento fisioterápico. Eles responderam que $50 \%$ dos pacientes foram sim participativos e colaborativos, $37 \%$ dos pacientes não foram participativos e colaborativos e $13 \%$ não fazem tratamento fisioterápico.

A participação e colaboração do paciente é muito importante para o tratamento fisioterapêutico, pois estamos sempre buscando uma melhor qualidade de vida para seu paciente com obtiveram Covid-19 (LIMA et. al. 2020). 


\section{RECIMA21 - REVISTA CIENTÍFICA MULTIDISCIPLINAR ISSN 2675-6218}

PERCEPÇÃO DE PACIENTES PÓS-COVID-19 ATENDIDOS NA UTI DE NANUQUE MG A RESPEITO DO TRATAMENTO FISIOTERAPÊUTICO: UM ESTUDO DE CASO.

Gráfico 8 - Ajuda do fisioterapeuta durante a internação na UTI em relação aos exercícios respiratórios e motores evitando possíveis complicações.

\section{Durante a internação na UTI o paciente teve ajuda do fisioterapeuta para a realização de exercícios respiratórios e motores para evitar possíveis complicações}

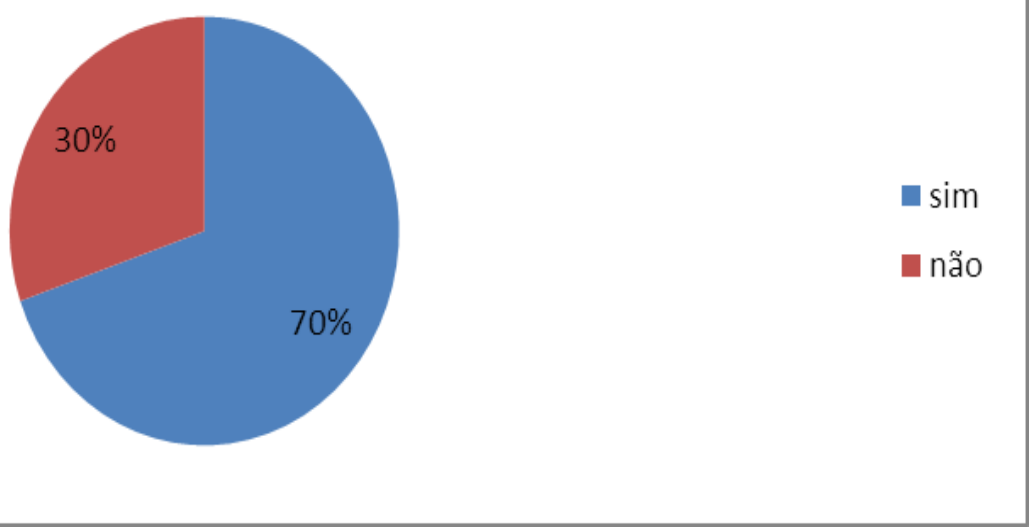

Fonte: Dados da pesquisa.

No Gráfico 8 perguntou-se aos familiares do paciente se durante a internação na UTI o paciente teve ajuda do fisioterapeuta para a realização de exercícios respiratórios e motores para evitar possíveis complicações. Eles responderam que $70 \%$ dos pacientes obtiveram sim a ajuda fisioterapêutica e $30 \%$ não obtiveram essa ajuda.

O objetivo do fisioterapeuta na UTI é melhorar a capacidade funcional geral dos pacientes e restaurar sua independência respiratória e física, diminuindo o risco de complicações associadas à permanência no leito. $O$ fisioterapeuta que trabalha no hospital atua na promoção e recuperação da saúde de pacientes acometidos por diferentes enfermidades, perpassando desde o préoperatório cirúrgico, atuando na educação e conscientização sobre técnicas respiratórias que irão prevenir acometimentos no pós-operatório (DANTAS, et. al. 2020). 


\section{RECIMA21 - REVISTA CIENTÍFICA MULTIDISCIPLINAR ISSN 2675-6218}

PERCEPÇÃO DE PACIENTES PÓS-COVID-19 ATENDIDOS NA UTI DE NANUQUE MG A RESPEITO DO TRATAMENTO FISIOTERAPÊUTICO: UM ESTUDO DE CASO. Viviele Santos Nascimento, Patricia Brandão Amorim

Gráfico 9 - Tratamento fisioterapêutico é eficaz no pós Covid-19.

\section{O tratamento da fisioterapia foi eficaz na doença.}

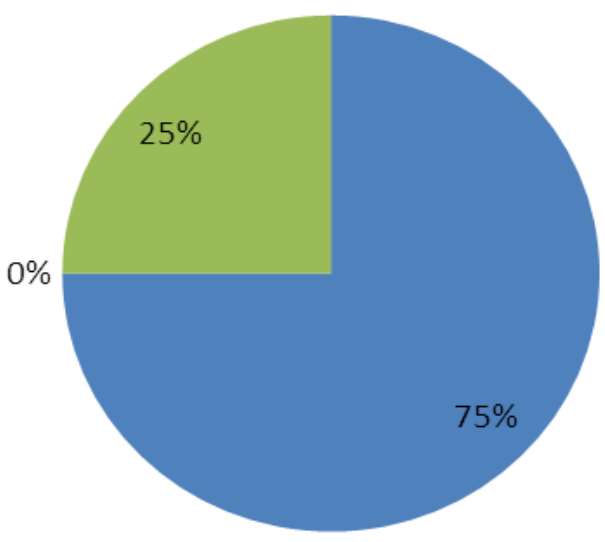

$\operatorname{sim}$

não

não realizou tratamento fisioterapêutico

Fonte: Dados da pesquisa.

No Gráfico 9 perguntou-se se o tratamento da fisioterapia foi eficaz na doença. 75\% disseram que sim o tratamento é muito eficaz, ninguém respondeu que não, e $25 \%$ não realizou tratamento fisioterapêutico.

Nas hospitalizações por Covid-19, o auxílio da fisioterapia é capaz de acelerar o processo de recuperação do paciente, diminuindo a necessidade de medicamentos e o risco de sequelas após a internação (KARSTEN \& MATTE, 2020). 


\section{RECIMA21 - REVISTA CIENTÍFICA MULTIDISCIPLINAR ISSN 2675-6218}

PERCEPÇÃO DE PACIENTES PÓS-COVID-19 ATENDIDOS NA UTI DE NANUQUE MG A RESPEITO DO TRATAMENTO FISIOTERAPÊUTICO: UM ESTUDO DE CASO.

Gráfico 10 - Expectativa do paciente em relação ao tratamento fisioterapêutico.

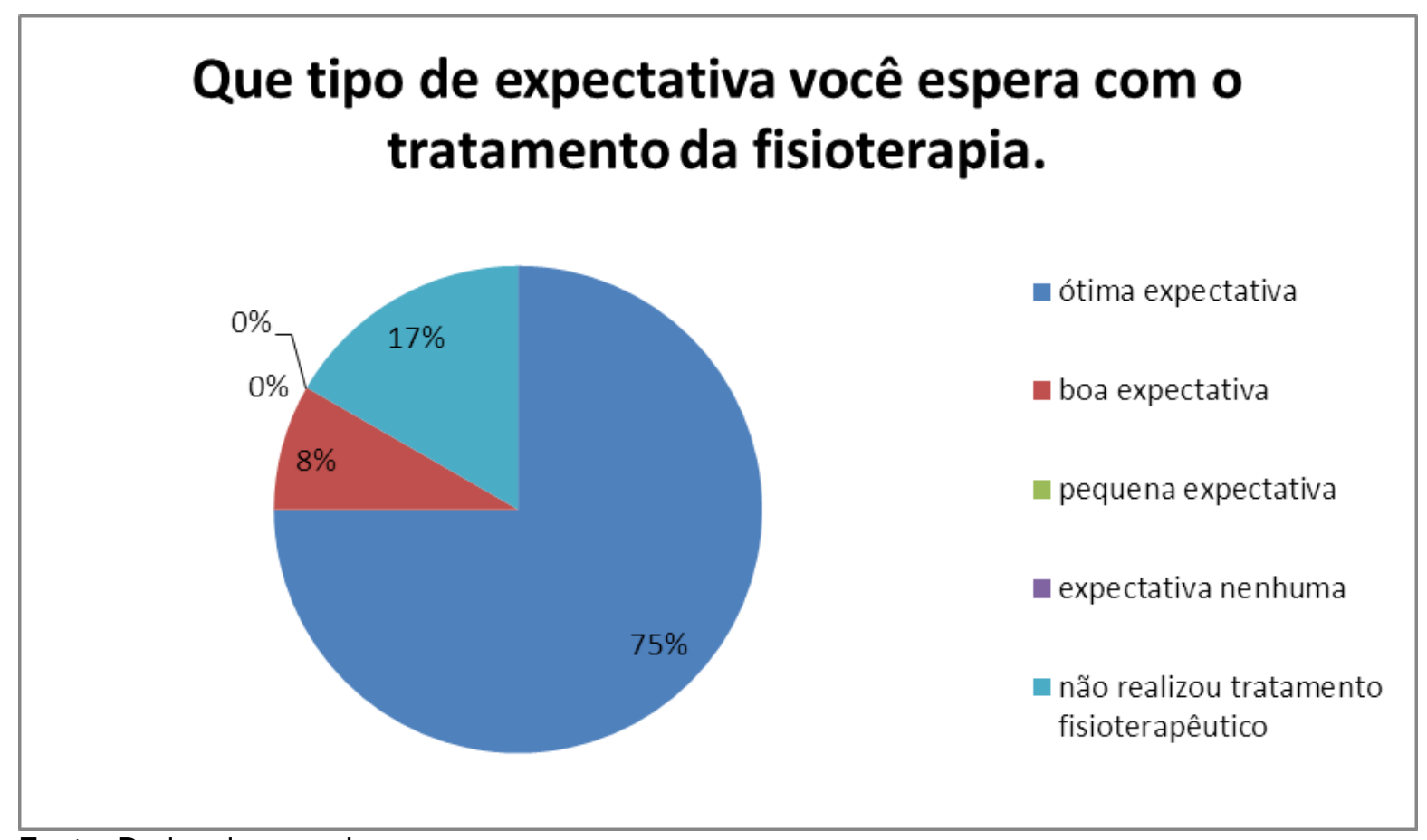

Fonte: Dados da pesquisa.

No Gráfico 10 perguntou-se ao paciente que tipo de expectativa espera com o tratamento da fisioterapia. Eles responderam que $75 \%$ tem ótima expectativa, $8 \%$ boa expectativa, não obteve resposta para pequena e nenhuma expectativa e 17\% não realizou tratamento fisioterapêutico.

Quando um paciente grave de Covid-19 consegue sair da UTI, é preciso dar continuidade ao tratamento em apartamento ou enfermarias até que ele esteja pronto para ter alta e possa se recuperar em casa. A dificuldade de dar alta ao paciente assim que ele sai da UTI se deve ao processo de enfraquecimento muscular que ocorre durante esse período, decorrente de falta de mobilidade e da alimentação estritamente controlada. É sabido que um paciente crítico pode perder entre $17 \%$ e $30 \%$ da massa muscular nos 10 primeiros dias de uma internação sob cuidados intensivos. Nos casos mais graves de Covid-19, a permanência na UTI pode durar de duas a três semanas (ou mais) (MUSUMECl, et. al. 2020).

Para auxiliar na recuperação desses pacientes ainda no hospital, o fisioterapeuta pode recorrer a exercícios com pesos para fortalecer a musculatura respiratória e periférica (braços e pernas) (SILVA, et. al. 2020). 

ISSN 2675-6218

PERCEPÇÃO DE PACIENTES PÓS-COVID-19 ATENDIDOS NA UTI DE NANUQUE MG A RESPEITO DO TRATAMENTO FISIOTERAPÊUTICO: UM ESTUDO DE CASO.

\section{CONSIDERAÇÕES FINAIS}

Conclui-se que a transição do paciente no ambiente hospitalar para o ambiente normal leva um tempo, pois é preciso que ele consiga retomar a autonomia de respirar sem ajuda de aparelhos. Após essa etapa é necessário utilizar técnicas motoras para avaliar a força do paciente, podendo utilizar equipamentos como dinamômetro isométrico, por exemplo. É imprescindível que o fisioterapeuta se qualifique para ser capaz de suportar toda a demanda e necessidades específicas de pacientes que tiveram Covid-19.

Nessa pesquisa destacou-se que os pacientes relataram uma percepção do tratamento fisioterápico sendo primordial, devido a sequelas que sofreram com a Covid-19. Onde $90 \%$ dos pacientes entrevistados relataram que a fisioterapia foi fundamental no tratamento pós-covid- 19 . Onde proporcionou o retorno do indivíduo ao mercado de trabalho de forma rápida, segura e eficaz, relatando também um bom desempenho na AVD'S (Atividades da vida diária).

Possivelmente a fisioterapia brasileira ainda não havia experimentado o período com tamanhos desafios e possibilidades de projeção e valorização, como este que foi vivenciado. Atuamos nos diversos cenários da pandemia (atenção básica, atuação hospitalar, desospitalização, atenção domiciliar, ambulatorial e remota), além de participar ativamente de atividades de pesquisas, inovação, ensino e desenvolvimento de políticas públicas.

Vale destacar a participação ativa e diferenciada dos fisioterapeutas intensivistas junto aos pacientes graves, reforçando a importância da permanência desses profissionais de forma ininterruptas nas UTIs, perfazendo às 24 horas diárias, cabe ainda aos fisioterapeutas documentarem sua atuação e publicarem os resultados de seus procedimentos e intervenções. Muito provavelmente o país e o mundo estarão diferentes após a pandemia, e os desafios impostos aos fisioterapeutas poderão se converter em estímulos para o aprimoramento e desenvolvimento profissional e das relações profissionais.

\section{REFERÊNCIAS BIBLIOGRÁFICAS}

ARARUNA, Fernanda Oliveira Sousa et al. Máscaras de tecido na prevenção da COVID-19: expectativa ou realidade? Revista de Saúde Coletiva da UEFS, v. 11, n. 1, p. 5929, 2021.

CUNHA, Gustavo Ferreira; SILVA, Denny Ericles Magalhães da. Reabilitação fisioterapêutica pós-COVID-19. 2021. Artigo Científico (Graduação) - Centro Universitário UniFG, Guanambi-BA, 2021.

CAMPOS, Letícia Fuganti et al. Parecer BRASPEN/AMIB para o enfrentamento do COVID-19 em pacientes hospitalizados. BRASPEN J, v. 35, n. 1, p. 3-5, 2020.

CHASQUEIRA, Marco; SILVA, Liliana. COVID-19: uma pandemia anunciada. Higeia: Revista Científica da Escola Superior de Saúde Dr. Lopes Dias, 2021. 


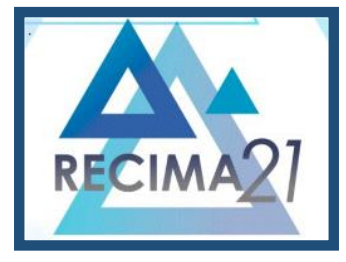

\section{RECIMA21 - REVISTA CIENTÍFICA MULTIDISCIPLINAR ISSN 2675-6218}

PERCEPÇÃO DE PACIENTES PÓS-COVID-19 ATENDIDOS NA UTI DE NANUQUE MG A RESPEITO DO TRATAMENTO FISIOTERAPÊUTICO: UM ESTUDO DE CASO.

DA SILVA, Cássio Magalhães et al. Evidências científicas sobre Fisioterapia e funcionalidade em pacientes com COVID-19 Adulto e Pediátrico. Journal of Human Growth and Development, v. 30 , n. 1, p. 148, 2020.

DA SILVA CRISTÓVAM, José Sérgio; HAHN, Tatiana Meinhart. O processo infeccioso da COVID19 no regime de dados no Brasil: a LGPD como vacina em teste no tratamento de dados pessoais no setor público. Revista Brasileira de Direito, v. 16, n. 3, p. 1-19, 2020.

DANTAS, Mariana et al. Contribuições das áreas: Farmácia, Fisioterapia e Psicologia aos pacientes internados em UTIs por COVID-19. Health Residencies Journal-HRJ, v. 1, n. 5, p. 75-91, 2020.

DE ALMEIDA COSTA, Felipe et al. COVID-19: seus impactos clínicos e psicológicos na população idosa. Brazilian Journal of Development, v. 6, n. 7, p. 49811-49824, 2020.

DE SOUSA NETO, Antonio Rosa; DE FREITAS, Daniela Reis Joaquim. Utilização de máscaras: indicações de uso e manejo durante a pandemia da covid-19. Cogitare Enfermagem, v. 25, 2020.

DIAS, V. M de C. H. et al. Testes sorológicos para COVID-19: Interpretação e aplicações práticas. J Infect Control [Internet], p. 1-41, 2020.

DO CARMO, Gabriela Pereira et al. Intervenções terapêutico-ocupacionais para pacientes com COVID-19 na UTI/Therapeutic-occupational interventions for patients with COVID-19 in ICU. Revista Interinstitucional Brasileira de Terapia Ocupacional-REVISBRATO, v. 4, n. 3, p. 397-415, 2020.

GARCIA, Leila Posenato. Uso de máscara facial para limitar a transmissão da COVID19. Epidemiologia e Serviços de Saúde, v. 29, p. e2020023, 2020.

GUIMARÃES, Fernando. Atuação do fisioterapeuta em unidades de terapia intensiva no contexto da pandemia de COVID-19. Fisioter. Mov., v. 33, 2020.

KARSTEN, Marlus; MATTE, Darlan Laurício; DE ANDRADE, Flávio Maciel Dias. A pandemia da COVID-19 trouxe desafios e novas possibilidades para a Fisioterapia no Brasil: estamos preparados? Revista Pesquisa em Fisioterapia, v. 10, n. 2, p. 142-145, 2020.

LIMA, Felicson Leonardo Oliveira et al. Diagnóstico da COVID-19: importância dos testes laboratoriais e dos exames de imagem. Research, Society and Development, v. 9, n. 9, p. e259997162-e259997162, 2020.

MARTINEZ, Bruno Prata et al. Papel do Fisioterapeuta em diferentes cenários de atuação à COVID19. ASSOBRAFIR Ciência, v. 11, n. Suplemento 1, p. 27-30, 2020.

MUSUMECI, Marcella Marson et al. Recursos fisioterapêuticos utilizados em unidades de terapia intensiva para avaliação e tratamento das disfunções respiratórias de pacientes com COVID19. ASSOBRAFIR Ciência, v. 11, n. Suplemento 1, p. 73-86, 2020.

NAGAMINE, Bruna Pereira; LOURENÇO, Lécia Kristine; CHAVES, Camila Teixeira de Oliveira Penna. Recursos fisioterapêuticos utilizados no Pós-COVID 19: Uma revisão bibliográfica. Research, Society and Development, v. 10, n. 7, p. e42910716785-e42910716785, 2021.

ORGANIZAÇÃO MUNDIAL DA SAÚDE. Doença por coronavírus 2019 (COVID-19): relatório de situação. Genebra: OMS, 2020. 


\section{RECIMA21 - REVISTA CIENTÍFICA MULTIDISCIPLINAR ISSN 2675-6218}

PERCEPÇÃO DE PACIENTES PÓS-COVID-19 ATENDIDOS NA UTI DE NANUQUE MG A RESPEITO DO TRATAMENTO FISIOTERAPÊUTICO: UM ESTUDO DE CASO.

PASCOAL, David Balbino et al. Síndrome Respiratória Aguda: uma resposta imunológica exacerbada ao COVID19/Acute Respiratory Syndrome: an exacerbated immune response to COVID19. Brazilian Journal of Health Review, v. 3, n. 2, p. 2978-2994, 2020.

ROLIM, Josiane Alves; DE OLIVEIRA, Aldecir Ramos; BATISTA, Eraldo Carlos. Manejo da ansiedade no enfrentamento da Covid-19. Revista Enfermagem e Saúde Coletiva-REVESC, v. 5, n. 1, p. 64-74, 2020.

SALLA, Larissa et al. COVID-19: Frequência de casos reagentes em profissionais de saúde de um hospital referência no Paraná. Research, Society and Development, v. 10, n. 9, p. e5310917662e5310917662, 2021.

SINHA, Neeraj; BALAYLA, Galit. Bateria sequencial de testes para COVID-19 para maximizar o valor preditivo negativo antes de operações. Revista do Colégio Brasileiro de Cirurgiões, v. 47, 2020.

SILVA, Juliana Herrero da et al. Descrição de um cluster da COVID-19: o isolamento e a testagem em assintomáticos como estratégias de prevenção da disseminação local em Mato Grosso, 2020. Epidemiologia e Serviços de Saúde, v. 29, p. e2020264, 2020.

STRABELLI, Tânia Mara Varejão; UIP, David Everson. COVID-19 e o Coração. Arq. Bras. Cardiol., v. 114, n. 4, abr. 2020.

SARAIVA, Ana Carolina Lustosa et al. Recursos terapêuticos para pacientes com sintomas leves da Covid-19. ASSOBRAFIR Ciência, v. 11, n. Suplemento 1, p. 65-71, 2020.

SALES, Emanuela Marques Pereira et al. Fisioterapia, funcionalidade e covid-19: revisão integrativa. Cadernos ESP-Revista Científica da Escola de Saúde Pública do Ceará, v. 14, n. 1, p. 68-73, 2020.

SCHUJMANN, Debora Stripari; ANNONI, Raquel. Papel da fisioterapia no atendimento a pacientes com Covid-19 em unidades de terapia intensiva. Fisioter. Pesqui., v. 27, n. 3 jul./sep. 2021.

TESINI, Brenda L. Coronavírus e síndromes respiratórias agudas (Covid-19, Mers e Sars). Manual MSD para profissionais da saúde. EUA: Merck Sharp \& Dohme Corp., 2020. 